\title{
Enlivening our cities: Towards urban sustainability and resilience
}

\author{
This article belongs to Ambio's 50th Anniversary Collection. Theme: Urbanization
}

\author{
Zahra Kalantari
}

Published online: 12 March 2021

Humanity is facing a broad range of sustainability challenges, degradation and loss of natural capital and ecosystem services, climate change and associated increases in the risk of ecological, meteorological, social, political and economic crisis and disasters (EU 2017)—all of them in different ways connected to cities and the current global urbanization (Pan et al. 2019). Cities world-wide are attracting more and more people and, as a result, urban studies is a rapidly growing and increasingly urgent field. Ambio has had a role in promoting insights broadly relevant for urban sustainability and resilience-and bringing them to policy and practice-by publishing and thus making visible some of the scientific discoveries that now provide part of the foundation for transformational urban research and practice. Over the years, many Ambio studies such as Folke et al. (1997), Ernstson et al. (2010) and Andersson et al. (2014) have taken extra steps to present not just study results but also new ways of understanding urban systems. By raising new questions as well as answering 'old' ones, these papers have engendered new research angles and more systemic understandings of cities and their multiple ties to sustainability-at scales from the very local to the global.

Chronologically first of the anniversary collection papers, Folke et al. (1997) took a regional-global approach to urbanization and demonstrated how cities are part of the global biosphere and dependent upon the life-supporting functions and services generated by ecosystems. This was one of the first papers to strongly position cities as drivers (and potential victims) of global changes to the biosphere, thus also connecting the human sphere to the nature/ecosphere. Ernstson and co-authors (2010) provide a, relative to its predecessors, more nuanced lens for urban resilience studies. Instead of the global support systems discussed in Folke et al. (1997) it discusses the importance of regionally generated ecosystem services for providing resources to support urban living and human wellbeing in cities. These local ecosystem services include the benefits that urban inhabitants and cities receive from ecosystem structures and processes present in cities, e.g. air quality regulation, stormwater protection, flood mitigation, water pollution control, local climate regulation, recreation, and opportunities to promote mental and physical health.

Synthesizing and expanding on earlier work by the authors, Andersson et al. (2014) posit that nature and active stewardship of nature are critical for urban resilience through, for example, the many connections to climate change adaptation, recreation and health. Following the framing offered by another Ambio paper led by Carl Folke (Folke et al. 2011), Andersson and colleagues explored ways of understanding what "reconnecting [cities] to the biosphere" may actually mean. The landmark Ambio papers are followed by the United Nations declaring 2021-2030 a "Decade of Ecosystem Restoration", a statement partly based on five years of extensive studies of urban green infrastructure and 'nature based solutions' $(\mathrm{NBS})^{1}$ following the publication of Andersson et al. in 2014. The growing understanding of the role of urban ecosystem services and how these could be managed fed into a research, implementation and, as often argued by the first two, transformation agenda centred around urban green and blue infrastructure and NBS Positioning green and blue infrastructure and NBS as part of a larger socialecological-technological system has helped researchers and policy makers alike bring together environmental, social,

\footnotetext{
${ }^{1}$ https://ec.europa.eu/programmes/horizon2020/en/news/towards-euresearch-and-innovation-policy-agenda-nature-based-solutions-renaturing-cities.
} 
and economic objectives (Kalantari et al. 2019; Frantzeskaki et al. 2021).

The system perspective proposed and used by Folke, Ernstson and Andersson (with co-authors) has thus continued to inform how we think about urban sustainability. Changes in environmental quality, climate, land use, demography, entitlements, urban morphology and green infrastructure have direct relevance for human well-being as well as ecosystem health. For example, in regions where increased population density places people in escalating conflict with nature, water-related stresses tied directly to disasters can be traced across economic, environmental, and societal impacts of droughts and floods. Continuing the line from Folke et al. (1997) human-induced factors (many of them urban) are also key drivers of climate change (IPCC 2020). Continuing to build our understanding cross scale dynamics, from the local decisions made by urban residents to global drivers of change, will, argues Haase and Frantzeskaki et al. (Haase 2021; Frantzeskaki et al. 2021) be essential for designing multi-level effective, efficient and resilient strategies and transition pathways for shifting the urban footprint into a positive force-for the climate as well as biodiversity and local communities. Acting on this growing understanding is, as argued already by Ernstson et al. (2010) and Andersson et al. (2014) a shared responsibility for us all.

Sustainable urbanization will require better understanding of complex interactions, their effects and feedbacks in the context of multidimensional urbanization, and associated complex governance structures, land use changes, climate change, shifting ecological baselines, socioeconomic factors, emergent risks like pandemics, diverse uses of urban space and resources, and new ways of taking on stewardship (Andersson 2021; Ernstson 2021; Folke et al. 2021). As repeatedly argued in the three original Ambio papers, future development of inclusive, productive, and resilient cities will require interactive collaborative learning by scientists, regional and local planners, designers, civil society and various decision-makers.

\section{REFERENCES}

Andersson, E. 2021. "Reconnecting cities to the Biosphere: Stewardship of green infrastructure and urban ecosystem services" where did it come from and what happened next? 50th Anniversary Collection: Urbanization. Ambio Volume 50. https://doi.org/10.1007/s13280-021-01515-z.

Andersson, E., S. Barthel, S. Borgström, J. Colding, T. Elmqvist, C. Folke, and A. Gren. 2014. Reconnecting cities to the biosphere:
Stewardship of green infrastructure and urban ecosystem services. Ambio 43: 445-453. https://doi.org/10.1007/s13280014-0506-y.

Ernstson, H. 2021. Ecosystems and urbanization: A colossal meeting of giant complexities. 50th Anniversary Collection: Urbanization. Ambio Volume 50. https://doi.org/10.1007/s13280-02101516-y.

Ernstson, H., S.E. van der Leeuw, C.L. Redman, D.J. Meffert, G. Davis, C. Alfsen, and T. Elmqvist. 2010. Urban transitions: On urban resilience and human-dominated ecosystems. Ambio 39: 531-545. https://doi.org/10.1007/s13280-010-0081-9.

EU Research and Innovation policy agenda for Nature-Based Solutions. 2017. https://ec.europa.eu/research/environment/ index.cfm?pg=nbs.

Folke, C., Å. Jansson, J. Larsson, and R. Costanza. 1997. Ecosystem appropriation by cities. Ambio 26: 167-172.

Folke, C., Å. Jansson, J. Rockström, P. Olsson, S.R. Carpenter, F.S. Chapin, A.-S. Crépin, G. Daily, et al. 2011. Reconnecting to the Biosphere. Ambio 40: 719-738. https://doi.org/10.1007/s13280011-0184-y.

Folke, C., А. Gren, J. Larsson, and R. Costanza. 2021. Cities and the Biosphere. 50th Anniversary Collection: Urbanization. Ambio Volume 50. https://doi.org/10.1007/s13280-021-01517-x.

Frantzeskaki, N., T. McPhearson, and N. Kabisch. 2021. Urban sustainability science: Prospects for innovations through a system's perspective, relational and transformations'approaches. 50th Anniversary Collection: Urbanization. Ambio Volume 50. https://doi.org/10.1007/s13280-021-01521-1.

Haase, D. 2021. Continuous integration in urban social-ecological systems science needs to allow for spacing co-existence. 50th Anniversary Collection: Urbanization. Ambio Volume 50. https://doi.org/10.1007/s13280-020-01449-y.

IPCC. 2020. An IPCC Special Report on climate change, desertification, land degradation, sustainable land management, food security, and greenhouse gas fluxes in terrestrial ecosystems. https://www.ipcc.ch/srccl/chapter/summary-for-policymakers/.

Kalantari, Z., C.S.S. Ferreira, B. Deal, and G. Destouni. 2019. Naturebased solutions for meeting environmental and socio-economic challenges in land management and development. Land Degradation \& Development. https://doi.org/10.1002/ldr.3264.

Pan, H., J. Page, L. Zhang, C. Cong, C. Ferreira, E. Jonsson, H. Näsström, G. Destouni, et al. 2019. Understanding interactions between urban development policies and GHG emissions: A case study in Stockholm Region. Ambio 49: 1313-1327. https://doi. org/10.1007/s13280-019-01290-y.

United Nations. 2020. UN Decade on Ecosystem Restoration.

Publisher's Note Springer Nature remains neutral with regard to jurisdictional claims in published maps and institutional affiliations.

\section{Zahra Kalantari $(\bowtie)$}

Address: Sustainable Development, Environmental Science and Engineering, KTH Royal Institute of Technology, Stockholm, Sweden.

Address: Department of Physical Geography, Stockholm University, Stockholm, Sweden.

e-mail: zahrak@kth.se; zahra.kalantari@natgeo.su.se 
We estimated the ecological footprint of cities in Baltic Europe and globally. The 29 largest cities of Baltic Europe appropriate for their resource consumption and waste assimilation an area of forest, agricultural, marine, and wetland ecosystems that is at least 5651130 times larger than the area of the cities themselves. Of the global human population, $20 \%$ (1.1 billion), living in 744 large cities worldwide, appropriate for their seafood consumption as much as $25 \%$ of the globally available area of productive marine ecosystems. The same cities' appropriation of forests for assimilation of $\mathrm{CO}_{2}$ emissions exceeds the full sink capacity of the world's forests by more than $10 \%$. If the goal as emphasized at the UN Habitat II Conference, 1996, is sustainable human settlements, the increasingly limited capacity of ecosystems to sustain urban areas has to be explicitly accounted for in city planning and development.

The populations of world's cities are growing by about 1 million people each week (1). In 1960, $34 \%$ of the human population of the world lived in urban areas, in 1990 this figure had grown to $44 \%$, and it is projected that $60 \%$ of the world population will be city dwellers in 2025 (2).

City inhabitants require productive ecosystems, outside the borders of the city, to produce the food, the water, and the renewable resources that are consumed inside the city. They also depend on ecological systems to provide clean air and to process waste. However, current city planning tends to take the work of ecosystems for granted. Since the capacity of ecosystems to generate nonmarketed natural resources and ecological services (3-5) is increasingly becoming a limiting factor for social and economic development (6), underestimating the importance of ecosystems is not a wise strategy, particularly not if the goal, as in the recent UN Conference on cities, is to develop sustainable human settlements.

In this paper we provide i) an estimate of the ecosystem area, or the 'ecological footprint' (7-10) that is appropriated by the 29 largest cities within the Baltic Sea drainage basin in northern Europe (Fig. 1). This region consists of 14 nations in both western and eastern Europe (11). ii) We also estimate the appropriation of global marine ecosystems for seafood consumption; and iii) of global forest ecosystems for assimilation of carbon dioxide $\left(\mathrm{CO}_{2}\right)$ released by 744 large cities worldwide, including 21 megacities (12). All cities in the study have more than 250000 inhabitants.

\section{ESTIMATING APPROPRIATED ECOSYSTEM AREAS OF CITIES}

\section{Renewable Resource Footprints of Baltic Cities}

We estimated the consumption of wood, paper, fibers, and food, including seafood, by people in the largest cities of the Baltic Sea drainage basin (1.7 million $\mathrm{km}^{2}$ ), and related this consumption to the area required to produce these resources in agricultural, forest and marine ecosystems (13). We based our quanti-

tative analyses on existing national data from this large-scale region with varying standards of living. Data on food and fiber consumption and land-use statistics, were obtained from the FAO computerized database Agrostat (14). Population data for the cities and land use in the region were obtained from Sweitzer et al. (15), and data on shelf sea areas and marine exclusive economic zones from the World Resources Institute on Diskette Database (16). The area of the cities was derived from an aerial photo-based GIS-data base combined with a GIS-data base of the Baltic Sea drainage basin (15). In addition, various statistical sources were used, as reported in Folke et al. (13).

Our calculations indicate that the 22 million inhabitants of the largest cities, corresponding to about $26 \%$ of the human population of the Baltic region, need an area from forest, agricultural and marine ecosystems for their consumption of wood, papers, fiber and food that is approximately 200 times the area of the cities themselves (17) (Table 1). The appropriated ecosystem area of forests was estimated to be 18 times larger, of agricultural land 50 times larger, and of marine systems 133 times larger than the area of the cities. If they were to receive their resources exclusively from the Baltic Sea drainage basin (which is not the 


\title{
Urban Transitions: On Urban Resilience and Human-Dominated Ecosystems
}

\author{
Henrik Ernstson, Sander E. van der Leeuw, \\ Charles L. Redman, Douglas J. Meffert, \\ George Davis, Christine Alfsen, Thomas Elmqvist
}

Received: 28 September 2009/Revised: 10 May 2010/Accepted: 16 June 2010/Published online: 29 July 2010

\begin{abstract}
Urbanization is a global multidimensional process paired with increasing uncertainty due to climate change, migration of people, and changes in the capacity to sustain ecosystem services. This article lays a foundation for discussing transitions in urban governance, which enable cities to navigate change, build capacity to withstand shocks, and use experimentation and innovation in face of uncertainty. Using the three concrete case citiesNew Orleans, Cape Town, and Phoenix - the article analyzes thresholds and cross-scale interactions, and expands the scale at which urban resilience has been discussed by integrating the idea from geography that cities form part of "system of cities" (i.e., they cannot be seen as single entities). Based on this, the article argues that urban governance need to harness social networks of urban innovation to sustain ecosystem services, while nurturing discourses that situate the city as part of regional ecosystems. The article broadens the discussion on urban resilience while challenging resilience theory when addressing human-dominated ecosystems. Practical examples of harnessing urban innovation are presented, paired with an agenda for research and policy.
\end{abstract}

Keywords Urban resilience $\cdot$ Ecosystem services . Social-ecological processes - Cross-scale interactions . Urban innovation - New Orleans - Cape Town · Phoenix

\section{INTRODUCTION}

Contemporary urbanization is a global multidimensional process, which manifests itself through changes in human population densities and land cover that are so rapid that we lag behind in understanding the process and its consequences. At the same time, we are facing an increasing uncertainty due to climate change, migration of people, and changes in the capacity of ecosystems to generate goods and services. In an urban context, this means that the traditional paradigm of planning for a predictable future is not only insufficient, but it may, in some ways, also be destructive. This article strives to lay a foundation for transitions in urban planning and governance, which enable cities to navigate change, build capacity to withstand shocks, and locate sources of experimentation and innovation in face of uncertainty.

The city can be thought of as an agglomeration of contested spaces that generate a range of urban services, from transport, housing, and medical aid, to jobs and financial markets (Harvey 1996). A presumption in this article is that such services are inextricably linked to ecological processes and the focus lies on such "ecosystem services," i.e., the benefits urban inhabitants and cities derive from ecosystem processes including, e.g., improved water and air quality, storm protection, flood mitigation, sewage treatment, micro climate regulation, and recreation and health values (Daily 1997; Bolund and Hunhammar 1999; Elmqvist et al. 2008). As ecological processes are in turn modified and entangled in social, and therefore political processes (most obviously through competing landuses), the city comes into view as constituted out of political social-ecological processes (Swyngedouw 2006; Pickett et al. 2008; Grimm et al. 2008). Based on this, a normative strategy for urban governance would be to maintain or even enhance essential ecosystem services and to accomplish this in ways that recognize the spatial distribution of ecosystem services and their relation to social equity. The two-fold proposition of this article is that resilience theory from ecological research can contribute to our thinking on this normative goal, and that cities can help 


\title{
Reconnecting Cities to the Biosphere: Stewardship of Green Infrastructure and Urban Ecosystem Services
}

\author{
Erik Andersson, Stephan Barthel, Sara Borgström, Johan Colding, \\ Thomas Elmqvist, Carl Folke, Åsa Gren
}

\begin{abstract}
Within-city green infrastructure can offer opportunities and new contexts for people to become stewards of ecosystem services. We analyze cities as social-ecological systems, synthesize the literature, and provide examples from more than 15 years of research in the Stockholm urban region, Sweden. The social-ecological approach spans from investigating ecosystem properties to the social frameworks and personal values that drive and shape human interactions with nature. Key findings demonstrate that urban ecosystem services are generated by social-ecological systems and that local stewards are critically important. However, land-use planning and management seldom account for their role in the generation of urban ecosystem services. While the small scale patchwork of land uses in cities stimulates intense interactions across borders much focus is still on individual patches. The results highlight the importance and complexity of stewardship of urban biodiversity and ecosystem services and of the planning and governance of urban green infrastructure.
\end{abstract}

Keywords Biodiversity - Ecosystem services . Property rights - Stewardship - Urban ecology . Urban social-ecological systems

\section{INTRODUCTION}

The rate of urban growth is unprecedented. The Earth System has become urbanized in the sense that decisions by the majority of the human population now living in cities affect the resilience of the entire planet (Seto et al.

Electronic supplementary material The online version of this article (doi:10.1007/s13280-014-0506-y) contains supplementary material, which is available to authorized users.
2011). Urban demand for ecosystem services is a major driver behind global environmental change but the choices people make are often disconnected from their environmental imprint in distant places (Folke et al. 1997; Grimm et al. 2008). Much of urban growth has been at the expense of the capacity of terrestrial and marine systems to generate and sustain essential ecosystem services (Foley et al. 2005) and is currently challenging biophysical planetary boundaries for the world as we know it (Rockström et al. 2009). There is an urgent need to reconnect people in urban areas to the biosphere (Folke et al. 2011).

Contemporary society, urban lifestyles, and changes, such as the decline of traditional land uses in the peri-urban landscape, have changed the way people in cities perceive and interact with the biosphere (Turner et al. 2004). The physical and mental distance between urban consumers and the ecosystems supporting them mask the ecological implications of choices made (Rees and Wackernagel 1996; Folke et al. 1997). Instead of oblivious consumers, cities need engaged stewards that can help redirect urbanization into a driver of positive change for humanity and the life-supporting systems that we depend upon. But how can people living in cities with urban lifestyles be reconnected to the biosphere? How do we ensure sustainable generation, management, and governance of ecosystem services for human well-being in cities, as well as ensure that cities contribute to incentives for better stewardship of distant landscapes and seascapes?

Though providing but a fraction of the ecosystem services consumed, urban landscapes represent key arenas for learning about the way humans interact with the environment and what sustainable ecosystem stewardship might entail (Miller 2005; Chapin et al. 2010). The focus of this paper is on lessons learnt for stewardship of ecosystem services within urban social-ecological systems (Berkes 